\section{Encontro Nacional da Sociedade Portuguesa de Química}

\begin{abstract}
A 27. ${ }^{a}$ edição do Encontro Nacional da Sociedade Portuguesa de Química (XXVII ENSPQ) decorreu de 14 a 16 de julho de 2021 na Universidade do Minho, em Braga. Foi necessário adaptar a realização deste Encontro ao momento em que vivemos, com a adoção de um modelo que permitisse a participação presencial e virtual dos cerca de 300 participantes inscritos. A situação pandémica da COVID-19 e as normas vigentes das autoridades de saúde determinaram uma participação presencial muito reduzida, no sentido de assegurar as melhores condições de segurança sanitária. Apesar das condicionantes, o XXVII ENSPQ foi uma excelente oportunidade para retomar alguma normalidade na divulgação e partilha da ciência.

A cerimónia de abertura contou com a presença do Prof. Filipe Vaz, Pró-Reitor para a Investigação e
\end{abstract}

Sessão de abertura do XXVII Encontro Nacional da Sociedade Portuguesa de Química. Da esquerda para a direita: Prof. Artur Silva (Presidente da SPQ), Prof. Filipe Vaz (Pró-Reitor para a Investigação e Projetos da Universidade do Minho) e Prof. Nuno Castro (Vice-Presidente para a Investigação e Inovação da Escola de Ciências da Universidade do Minho).

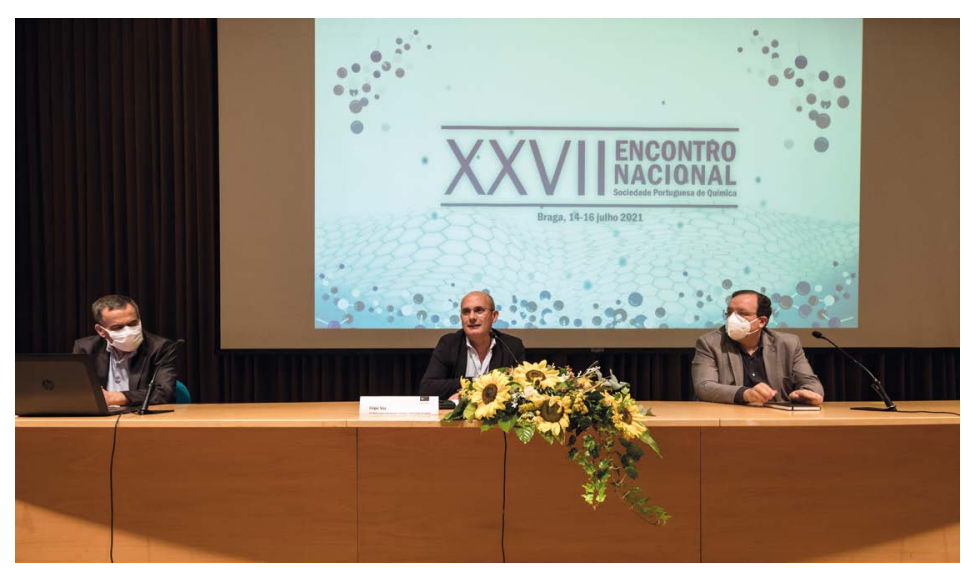

Projetos da Universidade do Minho, do Prof. Artur Silva, na qualidade de Presidente da Sociedade Portuguesa de Química, do Prof. Nuno Castro, Vice-Presidente para a Investigaç̧ão e Inovação da Escola de Ciências da Universidade do Minho e da

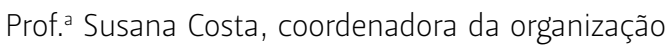
do XXVII ENSPQ. Seguiu-se a intervenção do Prof. Christopher Brett, da Universidade de Coimbra e atual Presidente da IUPAC, destacando a integração internacional da SPQ nesta organização mundial de divulgação e disseminação da Química.

Sob o tema "A Química e as Oportunidades na Sociedade Global", o programa científico foi muito variado e interdisciplinar e destacou a pertinência da Química para lidar com os desafios e as oportunidades societais, demonstrando a vitalidade e diversidade da química que se faz atualmente em Portugal e no mundo, num total de cerca de 250 comunicações de diversos tipos sob cinco temas agregadores: Materials chemistry and applications; Chemistry in life sciences; Food and natural products; Environment and water; Culture and education.

Tal como é habitual na reunião magna da SPQ, o programa iniciou-se com a atribuição do Prémio Ferreira da Silva do ano 2020 ao Professor Mário Nuno Berberan e Santos, do Instituto Superior Técnico - Universidade de Lisboa, pela sua contribuição para o avanço da Química. A lição plenária intitulada DeLightful molecules: selected studies in physical photochemistry consistiu numa interessante revisão da sua investigação em diversas áreas da fotoquímica física.

Ao longo dos três dias do Encontro foram proferidas lições plenárias de excelente nível por oradores de renome: Liquid-liquid phase coexistence in polyelectrolyte solutions: experimental model

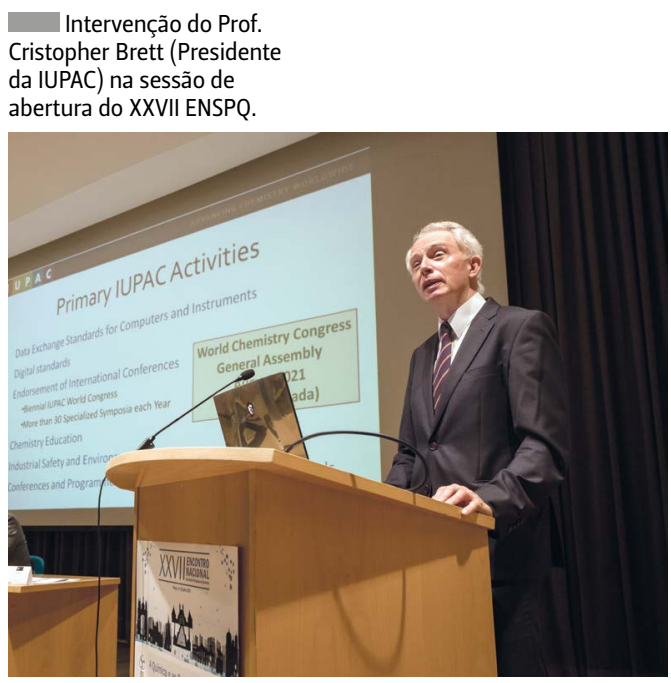




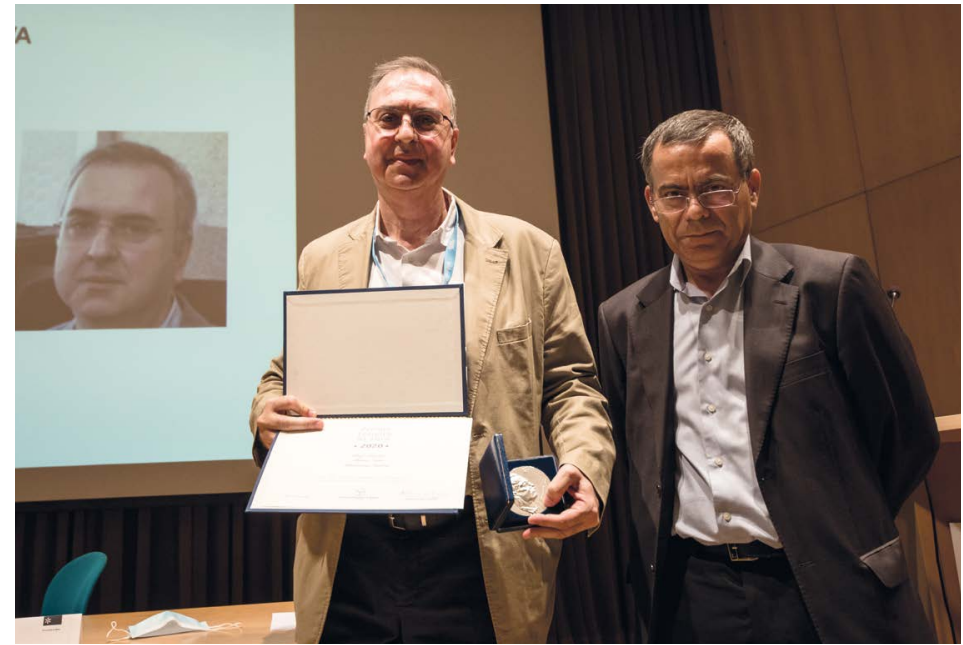

Entrega do Prémio Ferreira da Silva 2020 ao Prof. Mário Nuno Berberan e Santos pelo Prof. Artur Silva, Presidente da SPQ.

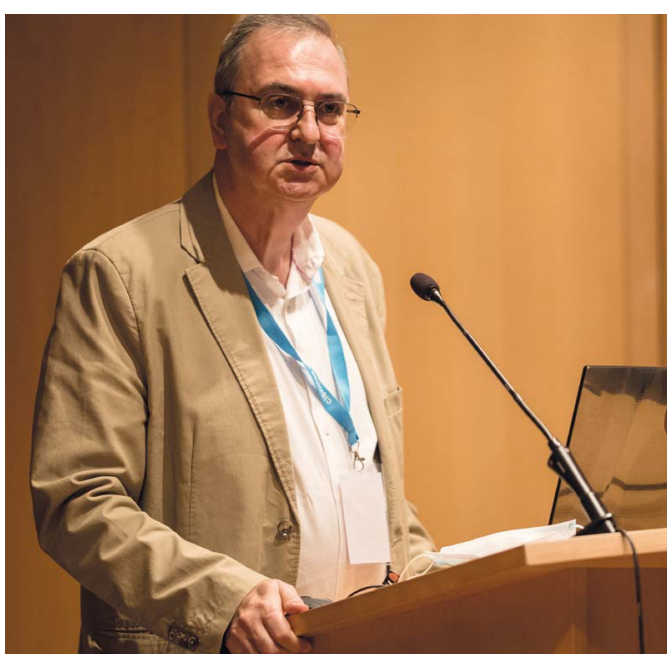

Lição plenária do Prof. Mário Nuno Berberan e Santos, Prémio Ferreira da Silva 2020. systems for RNA compartmentalization pela Prof. ${ }^{\mathrm{a}}$ Christine Keating (Pennsylvania State University, EUA); Probing and tuning photochemical reactions with isotopes, pelo Prof. Christian Bochet (Université de Fribourg, Suiça); Macro- and micro-plastic litter and increased COVID-19 based plastic pollution in the aquatic environment and landfills: treatment, environmental risks and policy solutions, pelo Prof. Damià Barceló (Institute of Environmental Assessment and Water Research / Catalan Institute for Water Research, Espanha) e Versatile and scalable nanocarbon chemistry, assembly, and application, pelo Prof. Milo Shaffer (Imperial College London, Reino Unido). A lição plenária associada ao Prémio Luso-Espanhol de Química, instituído pela SPQ e pela Real Sociedad Española de Química, atribuído anualmente, e em alternância, a químicos portugueses e espanhóis com projeção internacional, intitulada Can something that is called "Sub" be Superb? The case of Subphthalocyanines, foi apresentada pelo premiado do ano de 2020, Prof. Tomás Torres Cebada (Universidad Autónoma de Madrid, Espanha). Houve ainda duas lições plenárias associadas ao Prémio Luso-Francês de Química, numa colaboração entre a SPQ e a Société Chimique de France, que foram apresentadas pelo premiado de 2019, Prof. Pierre Braunstein (Université de Strasbourg, França) com o título Phosphorus- and NHC-based assembling ligands for metallophilic interactions, e pelo premiado de 2020, Prof. Pierre Dixneuf (Université de Rennes, França) intitulada Ruthenium catalysts for green transformations: from alkenes metathesis to $\mathrm{C}-\mathrm{H}$ bond functionalisations and useful ligands.

O programa decorreu com três sessões paralelas, sob os temas agregadores, nas quais foram apresentadas 18 keynotes, 24 comunicações orais convidadas, 21 comunicações orais, 62 comunicações flash e 111 comunicações em painel em formato digital, de várias instituições nacionais e empresas.

Convém também destacar o ciclo de quatro pré-conferências associadas ao XXVII ENSPQ que foram transmitidas em streaming (youtube.com/ feuptv) entre abril e junho, com a participação de jovens investigadores nacionais que pretendeu cobrir um leque diverso da intervenção da química, divulgando e incentivando à participação no Encontro. As pré-conferências foram proferidas por José Luis Díaz de Tuesta (IPB), Technologies to upcycle plastic solid wastes into nanostructured carbon materials (21 de abril); Pedro Góis (iMed-UL), Targeting N-terminal cysteines in bioconjugation (18 de maio); Ana Luísa Gonçalves (LEPABE-FEUP), Exploring the environmental applications of microalgae: $\mathrm{CO}_{2}$ capture and nutrients removal from wastewaters (2 de junho); e Mara Freire (CICECO-UA), Ionic liquid and water: the perfect duo to improve the extraction of high-value compounds from biomass (30 de junho).

$\mathrm{Na}$ tarde do dia 15 de julho decorreu também uma animada sessão de debate intitulada "A perceção pública da Ciência em tempos de pandemia", na qual se pretendeu refletir sobre a importância da ciência no contexto alargado da sociedade e da crise pandémica atual. A divulgação e comunicação da ciência ganha especial relevância pois torna-se indispensável o fornecimento aos cidadãos de informação de acordo com rigorosos critérios científicos, numa lógica de transparência e interesse público, em contraponto à desinformação de grande alcance 
e rápida propagação. Este tema tão pertinente foi moderado pelo produtor de rádio Adriano Cerqueira (RTP, Antena 1) com a participação do imunologista Miguel Castanho (IMM-UL), o bioquímico e divulgador de ciência David Marçal (FCSH-UNL), a geneticista Cecília Arraiano (ITQB-UNL) e a comunicadora Elsa Costa e Silva (CECS-UM). Este painel de oradores proporcionou um excelente e muito participado debate, com questões e comentários colocados pelos participantes. De seguida, teve lugar a Assembleia Geral da SPQ, presidida pelo Prof. Baltazar Castro.

O programa científico foi encerrado com a atribuição da Medalha Vicente de Seabra, destinada a premiar a alta qualidade, originalidade e autonomia do trabalho de investigação em Química desenvolvido em Portugal por um investigador de idade não superior a 40 anos. 0 galardoado de 2020 foi o Prof. Gonçalo Bernardes (Universidade de Lisboa, Portugal / University of Cambridge, Reino Unido) que apresentou a keynote Translational Chemical Biology: A small-molecule targeted RNA degradation approach - empowering RNA methylation analysis.

A sessão de encerramento do XXVII ENSPQ esteve a cargo do Prof. Joaquim Faria, Vice-Presidente da

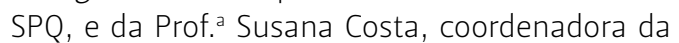
organização do Encontro, tendo sido feito o convite a todos os químicos portugueses para participar no próximo Encontro Nacional da Sociedade Portuguesa de Química, a decorrer em Aveiro em 2023.

O XXVII ENSPQ contou com o apoio institucional

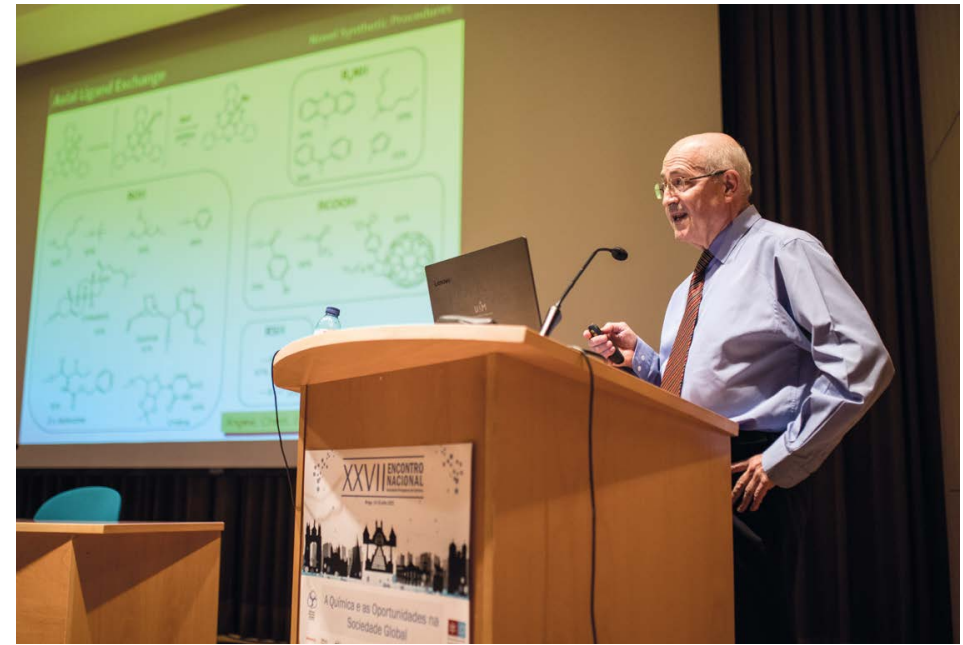

Lição plenária do Prof. Tomás Torres Cebada, Prémio Luso-Espanhol de Química 2020.

da SPQ e da Universidade do Minho, e com o patrocínio das empresas Bial, Bondalti, Bruker, Hovione, Grupo I.L.C., Izasa Scientific, Norleq, ThermoUnicam, Qlabo e Rotoquimica.

Mais informações sobre o Encontro e o livro de resumos completo pode ser consultado em xxviienspq.events.chemistry.pt.

\section{Susana Costa}

spc@quimica.uminho.pt

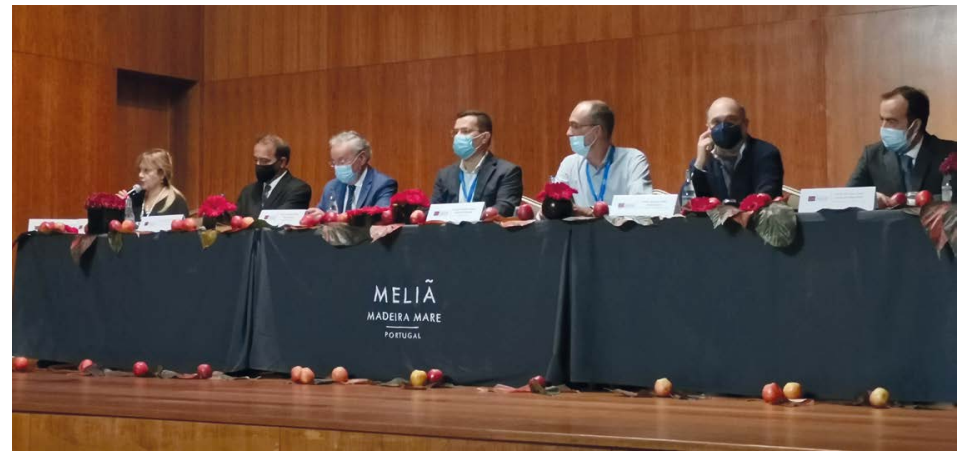

Mesa da sessão de abertura.

Entre os dias 5 e 8 de setembro de 2021, decorreu no Funchal (Ilha da Madeira), em formato híbrido, o XV Encontro de Química dos Alimentos (XV EQA) organizado pelo Grupo de Química dos Alimentos da Sociedade Portuguesa de Química (SPQ) com a colaboração conjunta do Centro de Química da Madeira (CQM) e Universidade da Madeira (UMa), tendo como

\section{Encontro de Química dos Alimentos}

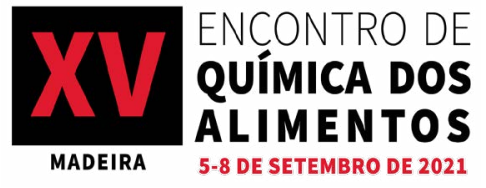

Chairman o Prof. José S. Câmara, Presidente do Grupo de Química dos Alimentos da SPQ desde 2018.

Com o tema central Estratégias para a excelência, autenticidade, segurança e sustentabilidade alimentar, participaram 275 congressistas dos quais 160 presencialmente e 115 de forma remota, via online. Foram submetidos 293 resumos dos quais 56 foram 